\title{
Control of Grid Connected PV Array using P\&O MPPT Algorithm
}

\author{
Madhavi S. Hajare ${ }^{1}$ \\ ${ }^{1}$ Department of Electrical Engineering, \\ Annasaheb Dange College of Engineering and Technology, \\ Ashta-416301 \\ Swapnil D. Patil ${ }^{2}$ \\ ${ }^{2}$ Department of Electrical Engineering, \\ Annasaheb Dange College of Engineering and Technology, \\ Ashta-416301
}

\author{
Rajendra B. Madake \\ ${ }^{3}$ Department of Electrical Engineering, \\ Annasaheb Dange College of Engineering and \\ Technology, Ashta-416301. \\ Anwar M. Mulla ${ }^{4}$ \\ ${ }^{4}$ Department of Electrical Engineering, \\ Annasaheb Dange College of Engineering and \\ Technology, Ashta-416301
}

\begin{abstract}
Renewable sources of energy are becoming more and more desirable in today's times, due to an increase in greenhouse effect, global warming and environmental awareness. This paper proposes a grid connected PV system that harnesses solar energy by converting sunlight into direct current electricity by using semiconductors, which will be implement by a complete Distributed Energy Resource system (DER). This project will contain a PV module and it will be controlled and optimized by using Maximum Power Point Tracking (MPPT) algorithm. P \& O MPPT formula is used in this paper. $P \& O$ MPPT algorithm is based on the calculation of the PV output power and the power change by sampling PV current and voltage. An isolation transformer is used in this module to integrate the single-phase inverter with grid. Switching of the boost converter and operation of the single-phase inverter as well as its integration with the grid is controlled by PI Controllers. Detailed mathematical and engineering analysis for the simulated results will be followed with the help MATLAB software.
\end{abstract}

Keywords-Maximum Power Point Tracking System, Perturb and Observe Algorithm, Isolation Transformer, Photovoltaic, Boost converter.

\section{INTRODUCTION}

The decrease of non-renewable energy sources and growing problem of environmental pollution, has forced us to look for better energy sources. The research being carried out on utilization of renewable energy such as solar energy, wind energy as soon has made it possible to utilize this abundant quantity of renewable energy sources in our day to day life more efficiently and economically. As we all know solar energy is the most abundant renewable energy source at present in the world. The Distributed generation headed by the photovoltaic (PV) generation can solve all electrical power requirements in remote areas. Existing electricity supply system fails to meet peak power demand. This is a major cause of concern for many countries. The photovoltaic grid connected system greatly overcomes this problem.. Solar energy is considered as the most popular source of renewable energy because of its round the clock availability during the day, easy commissioning, decreasing costs and increasing efficiency. The output power produced by the photovoltaic modules is intermittent in nature and depends on the intensity of solar radiation and temperature of solar cells [1]. As the efficiency of the commercially available solar cells is low, it is important to track the maximum power point. For this purpose, different MPPT algorithms are used. MPPT is used to increase output voltage of PV and to ensure that the PV is operated at the maximum power point. Different MPPT methods have been presented in literature [2]. In this paper we implement the Perturb \&Observe (P\&O) algorithm for the MPPT in which the voltage is slightly perturbed in the direction of the increasing power to find the MPPT point [34]. A DC - DC boost converter increases the input voltage by controlling its switching [5]. After that a single-phase grid tied inverter is used to convert the DC input into AC. We have used a low pass filter in order to remove the high frequency harmonics which are an obstacle to our grid integration. The Grid integration with the PV module is done by implementing an isolation transformer. All of these converters and circuits require a significant degree of control and tuning to serve their intended purpose. For this case PI controller are used and are accordingly properly tuned to give the best results.

\section{SYSTEM CONFIGURATION}

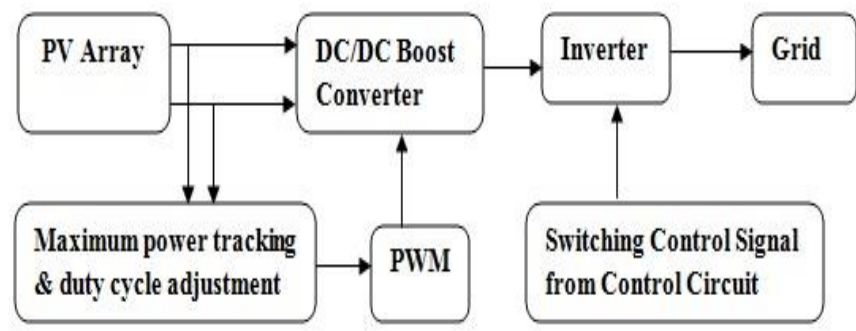

Fig.1. Block diagram of grid-connected PV System

The configuration of the grid connected PV is shown in fig. 1 in which the PV is connected to the DC-DC converter which is work to control dc output from unregulated DC input by adjusting duty cycle. The DC-DC boost converter is controlled using PWM which is done by varying the duty cycle for the boost converter. P \& O MPPT algorithm generates the duty cycle. A single-phase inverter is used to convert photovoltaic DC voltage into line frequency $\mathrm{AC}$ 
voltage. A Sinusoidal Pulse Width Modulation (SPWM) switching control is designed to control the inverter [6]. The employed scheme also ensures that the DC-link voltage remains stable without varying rapidly thus ensuring a smooth system operation. An isolation transformer is also designed to synchronize the inverter with the grid voltage. Finally, LR filter was connected between the inverter and the grid to fulfill the standard specifications of current harmonics injected to the grid. The inductor offers high impedance to high frequency signals and low impedance to low frequency signals, therefore its series connection suppresses the AC ripples making it act as a low pass filter.

\section{SYATEM CONTROL}

\section{A. MPPT control of boost converter}

Current-voltage (I-V) characteristic of a PV depends on the intensity of the irradiation \& the temperature. Temperature influences the PV output voltage while solar irradiance affects PV output current. There is a maximum power point (MPP), at which the array operates with the maximum efficiency.

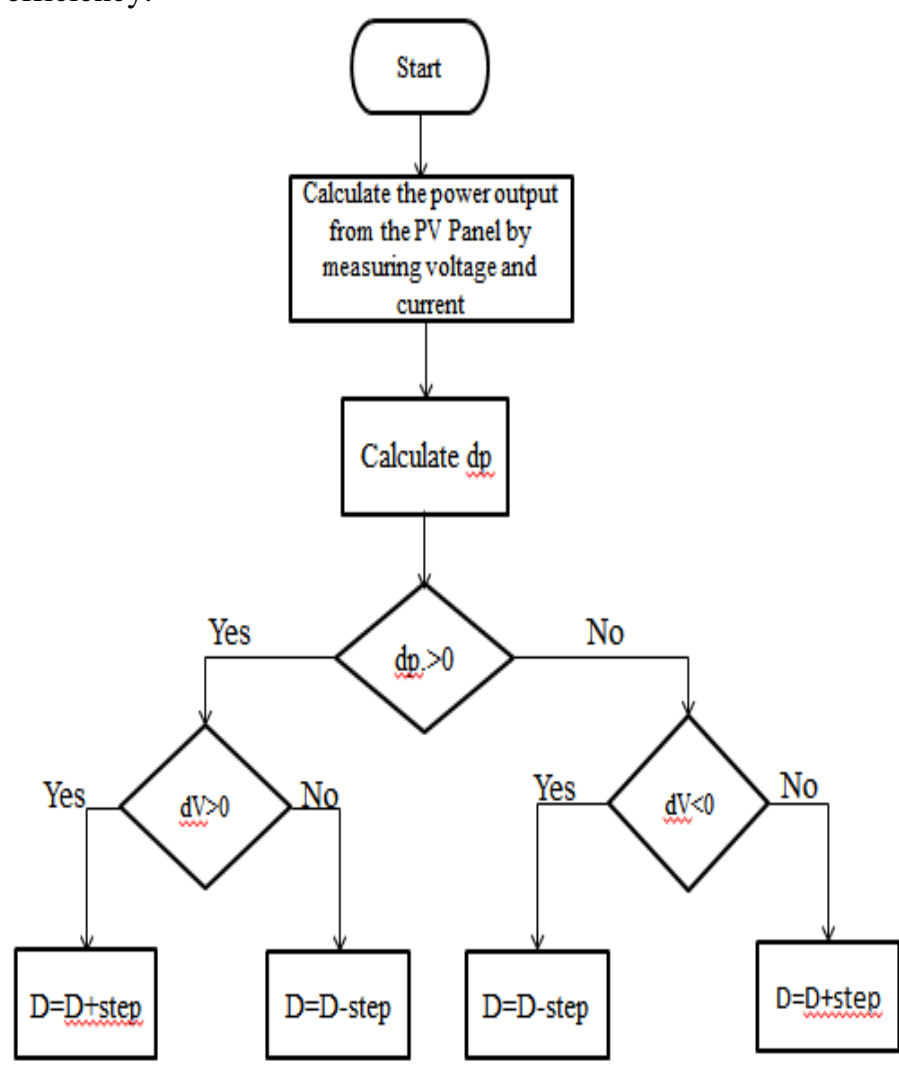

Fig. 2. Mechanism of P\&O algorithm

Based on the impedance matching principle the power output of a circuit is highest when the source impedance matches with the load impedance. The MPPT algorithm does this impedance matching by adjusting the duty factor $\mathrm{D}$ of the DC-DC converter. The input and output impedances are related by the following expression [7].

$$
\mathrm{R}_{\text {in }}=\left(1-D^{2}\right) R_{\text {losd }}
$$

$\mathbf{D}$ is the duty cycle;

\author{
$\boldsymbol{R}_{\tilde{\text { in }}}$ is the PV impedance; \\ and $\boldsymbol{R}_{\text {load }}$ is the load impedance.
}

In this paper we use the P\&O algorithm for MPPT. The principle of this approach is that it will perturb the reference voltage by observing the system response to determine the direction of the next perturbation. The reference voltage perturbations are performed in the direction in which the power should increase [8]. The control circuitry consists of two PI controllers which have an integral gain of 100 and a time constant of 0.1 tuned by trial and error, the reference voltage is being fed into the first PI controller, which is being employed for the voltage control and drives the PV system voltage towards the MPPT voltage [9]. This is followed by another PI controller which acts as a current controller and drives the system current towards the MPPT current. The output of the control loops is fed to the comparator which generates the PWM to drive the boost converter ensuring that the system operates at the desired maximum power point [10].

\section{B. Isolation Transformer for single phase system}

Isolation Transformer (IT) control subsystem is one of the important element of grid connected inverters as it plays a key role in synchronize the inverter with the grid voltage, current, frequency and phase angle [11].

\section{Control scheme of single-phase grid-tie inverter}

A grid-tie inverter is used to convert direct current (DC) electricity into alternating current (AC) and has the ability to synchronize and interface with the utility grid [12]. Inverter operation can be divided into two parts: First part is synchronizing and the second part is power transmitting. During synchronization, the inverter is producing the output in phase with the grid. This is performing by sampling the sine wave and setting phase shift to zero. This un-shifted sine wave is rectified and compare with high frequency triangle wave to generate SPWM signal [13]. To produce four sets of switching signal an AND operation is performed between the SPWM and the square wave signal. Using this type of switching and zero phase shifts occurring the inverter output voltage.

\section{SIMULATION DESIGN AND RESULTS}

Fig.3 shows the simulation model for the full system which has been implemented in MATLAB showing the PV module, Dc-Dc boost converter, P\&O MPTT algorithm, single phase grid tie inverter and the employed control schemes for the MPPT control via Dc-Dc boost converter, single phase inverter $\&$ the transformer for synchronizing the single-phase inverter with the Gird. MATLAB simulation is used for the 40 W solar PV systems to verify the validity of the system and the employed control schemes. The system parameters used for performing the simulations are listed in Table 1. The system control was optimized by configuring the controller parameters and by employing the P\&O MPPT scheme. Controlled by the same phase as the grid. With inverter and grid voltage in phase the zero crossing of both voltages is detected. When zero crossing is found contact between grid and inverter, then it activates and connects the grid and inverter together. After both voltages are connected the inverter begins to transmit power 


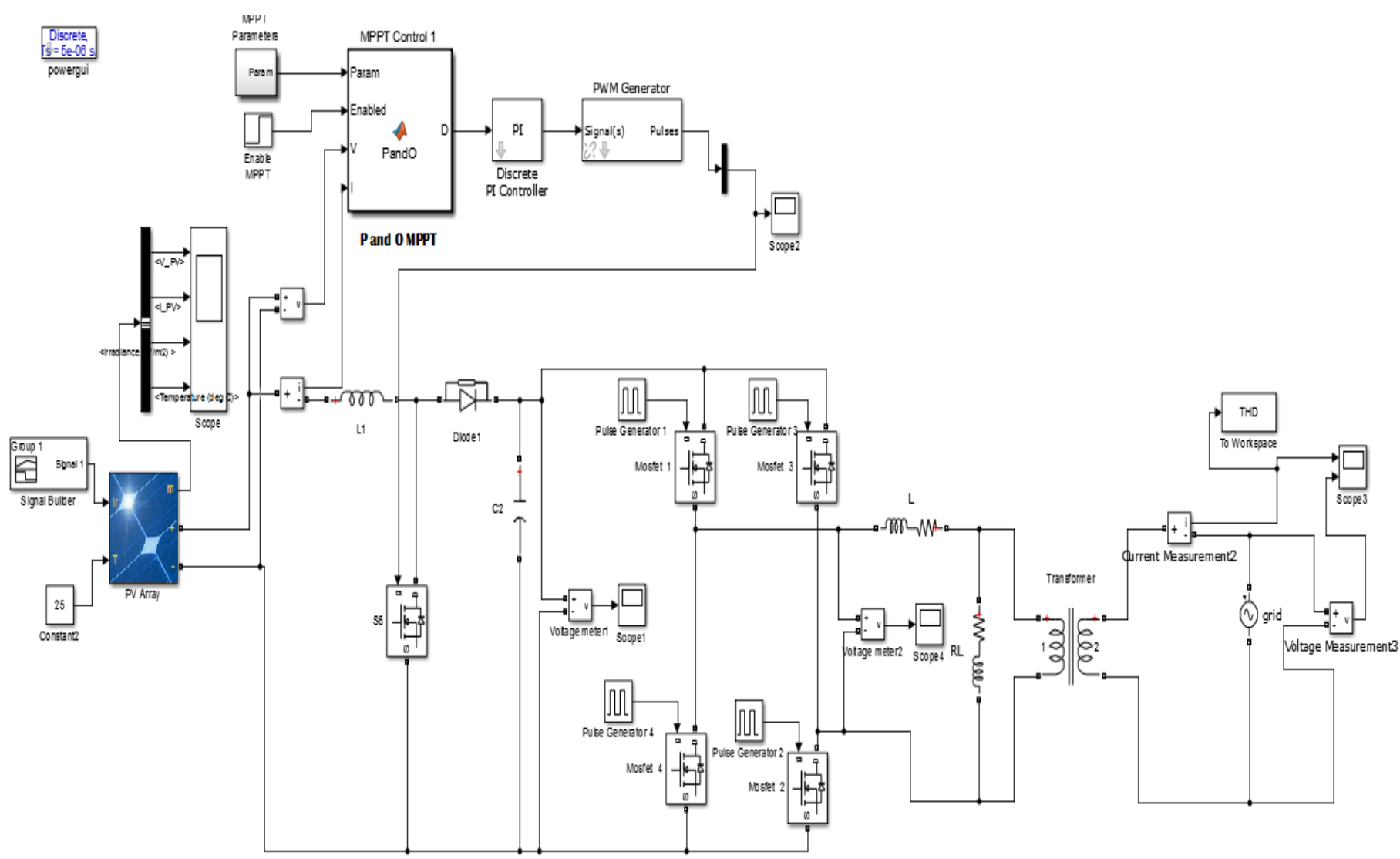

Fig.3. Simulation of Grid connected PV system with P\&O as MPPT.

into the grid. The inverter used in our application delivers the power from the PV to the grid via the boost converter, where the dc link voltage ensures that there are no power losses [14$15]$.
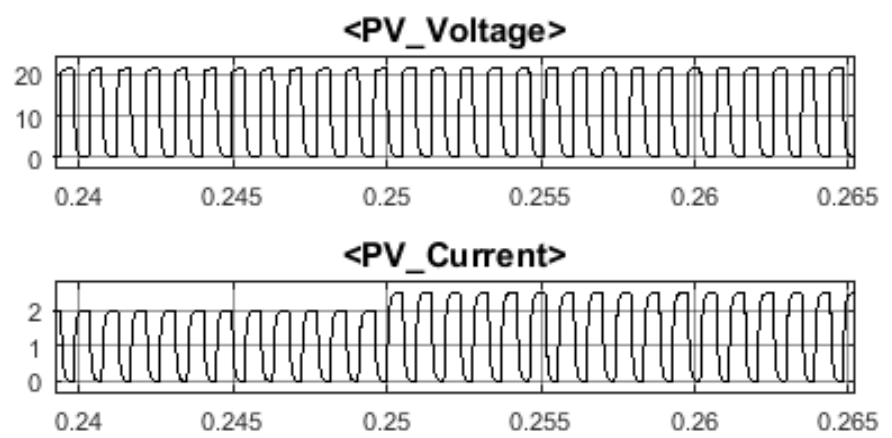

< Irradiance $(\mathrm{W} / \mathrm{m} 2)>$

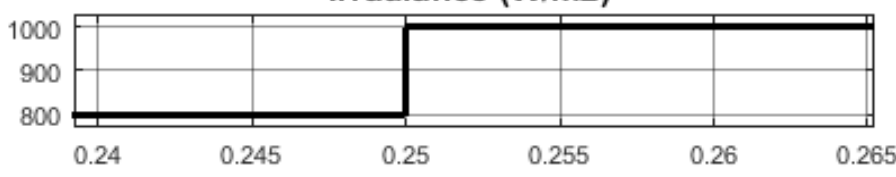

$<$ Temperature $(\operatorname{deg} \mathrm{C})>$

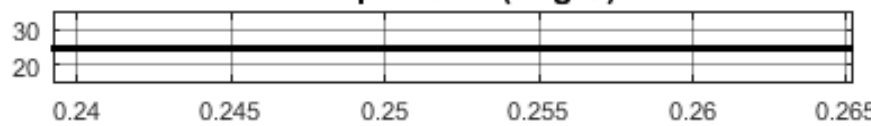

Fig.4. Output voltage and current with MPPT for different irradiation level at 25Deg.

Fig.4 shows the transient and steady state response of the voltage and current output of the PV array, from the results we can see that the output voltage of the PV panel settles down at $21 \mathrm{~V}$ while the current value changes depending on

the irradiation. corresponds to the irradiation values used in the simulations i.e. $800 \mathrm{~W} / \mathrm{m} 2$ and $1000 \mathrm{~W} / \mathrm{m} 2$.

Table.1. System Parameters
\begin{tabular}{|l|c|}
\hline \multicolumn{1}{|c|}{ Parameters } & Value \\
\hline Power of PV system & $40 \mathrm{~W}$ \\
\hline PV array Output Voltage & $21 \mathrm{~V}$ \\
\hline $\begin{array}{l}\text { Output voltage of Boost } \\
\text { converter }\end{array}$ & $80 \mathrm{~V}$ \\
\hline $\begin{array}{l}\text { Output Voltage of Single Phase } \\
\text { Inverter }\end{array}$ & $80 \mathrm{~V}$ \\
\hline Grid rating & $230 \mathrm{~V}, 50 \mathrm{~Hz}$ \\
\hline
\end{tabular}

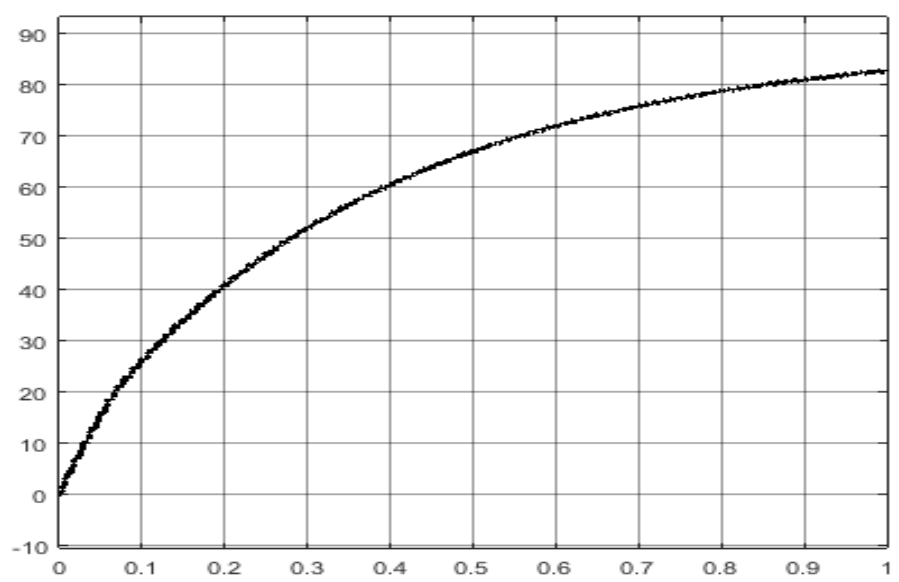

Fig. 5 shows the PV panel output voltage is boosted to80V DC by using boost converter. 


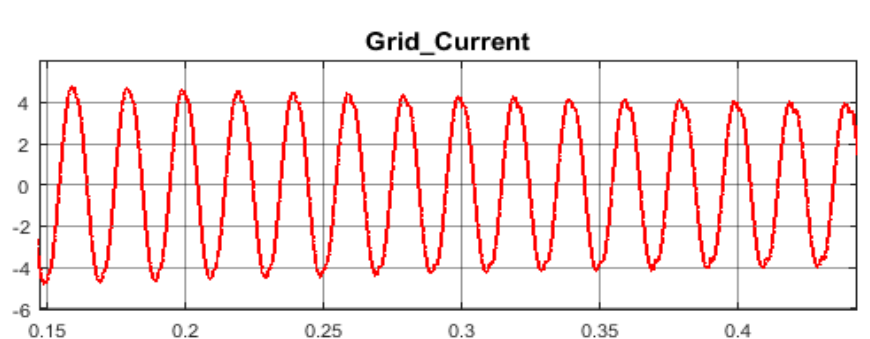

Grid_Voltage

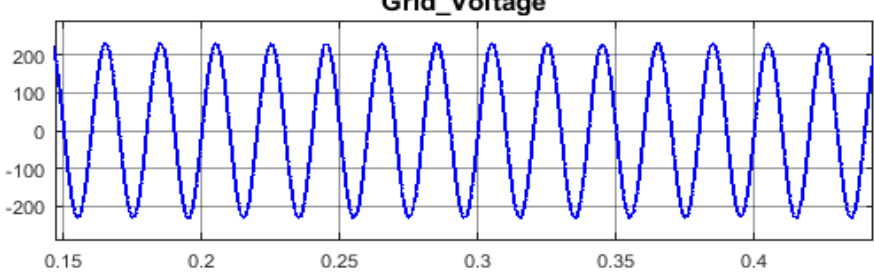

Fig.6. AC Output Voltage and Current Waveform with Grid Connection

Fig. 6 shows the sinusoidal output voltage and current waveform of the PV system has been successfully integrated with the grid which is rated at $230 \mathrm{~V} \& 50 \mathrm{~Hz}$.

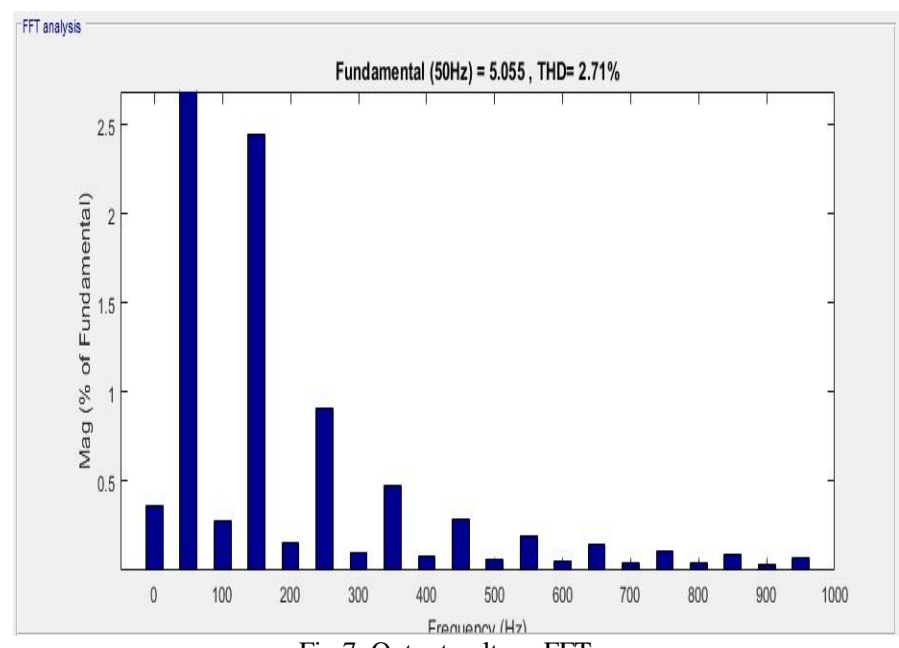

Fig.7. Output voltage FFT

It is Observed that the total harmonic distortion (THD) of 2.71\%.Fig.7 Show the Fast Fourier Transform (FFT) of Output Voltage. FTT demonstrates that the fundamental harmonic components lie at $50 \mathrm{~Hz}$ and rest of the harmonic components are negligible.

\section{CONCLUSION}

A grid connected PV System was implemented and its effectiveness was confirmed by the simulation results in MATLAB which gave a sinusoidal wave for the grid current. The system was also operated at the MPPT point by applying the $\mathrm{P} \& \mathrm{O}$ based MPPT algorithm. Control schemes are applied for the single-phase inverter, boost converter and PLL. Control scheme for the MPPT is applied by controlling the duty cycle for boost converter. The single-phase inverter is also synchronized with grid by using phase locked loop.

\section{REFERENCES}

[1] Roberto Faranda, Sonia Leva" Energy comparison of MPPT techniques for PV Systems" WSEAS transactions on power system Issue 6, Volume 3, June 2008

[2] Mohammed A. Elgendy, Bashar Zahawi, Senior Member, IEEE, and David J. Atkinson." Assessment of Perturb and Observe MPPT Algorithm Implementation Techniques for PV Pumping Applications", IEEE transactions on sustainable energy, VOL. 3, NO. 1, January 2012

[3] A. Pandey, N. Disrupt, and A. K. Mukherjee , "Design issues in implementing MPPT for improved tracking and dynamic performance" ,IEEE IECON, 2006, pp. 4387439

[4] Qing Chang Zhong and Tomas Henrik, "Control of Power Inverters in Renewable Energy and Smart Grid Integration". UK: Wiley-IEEE Press, 2013

[5] Roberto F. Coelho, Filipe Concern, Denizen C. Martins," a study of the basic dc-dc converters applied in maximum Power point tracking", 978-1-4244-3370-4/09/\$25.00 (C) 2009 IEEE

[6] Kavita Nanshikar and Aditi Desai, "Simulation of P \& O Algorithm using Boost Converter," International Journal of Innovative Researchin Electrical, Electronics, Instrumentation and Control Engineering,vol. 4, no. 2, pp. 130-135, April 2016

[7] T. Esram, and P.L. Chapman, "Comparison of Photovoltaic Array Maximum Power Point Tracking Techniques", IEEE Trans. Energy Conv., vol.22, no.2, June, 2007, pp.439-449 .

[8] Nicola Femia, Member, IEEE, Giovanni Petron, Giovanni Spagnuolo, Member, IEEE, and Massimo Vitelli" Optimization of Perturb and Observe Maximum Power Point Tracking Method" IEEE transactions on power electronics, VOL. 20, NO. 4, JULY 2005

[9] S. K. Kollimalla, and M. K. Mishra, "Adaptive Perturb \& Observe MPPT Algorithm for Photovoltaic System”, 2013 IEEE Power and Energy Conference at Illinois (PECI), pp. 42-47, 2013.

[10] Hurng-LiahngJou; Wen-Jung Chiang ; Jinn-Chang Wu "Voltage-mode grid-connected solar inverter with high frequency isolated transformer "International Symposium on Industrial Electronics IEEE 2009 10.1109/ISIE.2009.5213218

[11] Ahmed A. A. Hafez, Daniel Montesinos-Miracle and Anto SudriàAndreu "Simple Maximum Power Point Controller for Single-Phase Grid-Connected PV System" Proceedings of the 14th International Middle East Power Systems Conference (MEPCON'10), Cairo University, Egypt, December 19-21, 2010

[12] Almas Hossain Mollah1, Prof. G KPanda2, Prof. P KSaha3 "Single Phase Grid-Connected Inverter for Photovoltaic System with Maximum PowerPoint Tracking" International Journal of Advanced Research in Electrical, Electronics and Instrumentation Engineering (An ISO 3297: 2007 Certified Organization)Vol. 4, Issue 2, February 2015

[13] Paukner, F. L., et al. "Dynamic behavior of the PV Grid-connected inverter based on L and LCL filter with active damping control." Power Electronics Conference and 1st Southern Power Electronics Conference (COBEP/SPEC), 2015 IEEE 13th Brazilian. IEEE.

[14] Snehal Sunil Bulle ; S. D. Patil ; V. V. Kheradkar "Implementation of incremental conductance method for MPPT using SEPIC converter" International Conference on Circuit ,Power and Computing Technologies (ICCPCT), 2017, IEEE Conference Publications, ISBN: 978-1-5090-4967-7 , DOI: 10.1109/ICCPCT.2017.8074234.

[15] Rajkumari R. Patil ; Smita P. Patil ; Swapnil D. Patil ; Anwar M. Mulla, "Designing Of Z-source inverter for photovoltaic system using MATLAB/SIMULINK" International Conference on Circuit ,Power and Computing Technologies (ICCPCT), 2017, IEEE Conference Publications, DOI: 10.1109/ICCPCT.2017.8074331
ISBN: 978-1-5090-4967-7, 